\title{
The Relationship between Emotional, Social, Cultural, Spiritual Intelligence and EFL Teachers' Teaching Effectiveness
}

\author{
Jahanbakhsh Nikoopour \\ Islamic Azad University, Tehran North Branch, Iran \\ Nadimeh Esfandiari \\ Islamic Azad University, Tehran North Branch, Iran
}

\begin{abstract}
The present study attempted to investigate the relationship between EFL teachers' emotional, social, cultural, spiritual intelligence and their teaching effectiveness in EFL contexts. Teaching effectiveness was investigated as perceived by EFL teachers, observers and learners based on a data-triangulated procedure. A total of 126 EFL teachers, 266 learners and 31 EFL observers selected randomly from various educational districts in Tehran participated in the study. The EFL teachers were required to answer self-report questionnaires of Teaching Effectiveness Scale (TES), Emotional Intelligence Questionnaire (TEIQue), Cultural Intelligence Scale (CQS), Tromsø Social Intelligence Scale (TSIS) and Integrated Spiritual Intelligence Scale (ISIS) respectively. The EFL observers and learners were also required to answer Teaching Effectiveness Scale (TES) to reveal their perception of their teachers' teaching effectiveness. The study revealed that among EFL teachers, there was a significant correlation between teaching effectiveness and TEQ, but the correlation between teaching effectiveness and the three other types of intelligence (SQ, CQ, \& SPQ) was not significant. The three groups of participants (teachers, observers, and learners) showed a significant difference in their perception of effective teaching. In further analysis, gender made a significant difference in TEQ, but female and male EFL teachers did not show a significant difference in their CQ, SQ, SPQ and effective teaching. University degree caused a significant difference in SQ and TEQ, but not in TE, SPQ and CQ. However, teaching experience and age made a significant difference in all four variables under the study.
\end{abstract}

Index Terms - emotional, social, cultural, spiritual intelligence, teaching effectiveness

\section{INTRODUCTION}

The characteristics of effective teachers have been investigated by some researchers outside its domain (DemmonBerger, 1986; Lowman, 1996; Witcher, Onwuegbuzie, \& Minor, 2001; Koutsoulis, 2003) and inside the realm of foreign language education (Bernhardt \& Jammadou, 1987; Lafayette, 1993; Mollica \& Nuessel, 1997; Freeman \& Johnson, 1998; Schulz, 2000; Vélez-Rendón, 2002). The EFL teachers' teaching effectiveness was based on some different variables such as their knowledge of subject matter, content knowledge, professional development, and contextual knowledge.

There are some universal characteristics shared by effective teachers; however, some of their attributes are specifically related to their domain. Some studies have been done outside the domain of foreign language education, investigating the characteristics of effective teaching. Several studies focused on some individuals who characterized effective teachers such as good students and weaker students (Koutsoulis, 2003), male and female students (Witcher et al., 2001; Minor, Onwuegbuzie \& Witcher, 2002), teachers and students (Lang, McKee \& Conner, 1993), and students with different majors (Check, 1986). The domain of foreign language education is exclusively unique in terms of linguistic knowledge, pedagogical content knowledge, professional development, and contextual knowledge; thus, the characteristics of effective EFL education should be elucidated specifically in its own domain, not generalizing the outcomes of general education to EFL teaching. In some other studies (Demmon-Berger, 1986; Brosh, 1996; Koutsoulis, 2003; Lang et al., 1993; Lowman, 1996; Witcher et al., 2001), the characteristics of effective teachers were investigated and found to have strong influence on the students' learning and achievement.

The proposal of Multiple Intelligence Theory (Gardner, 1983) stimulated some researchers (Armstrong,1995; Chen \& Gardner,2005; McMahon \& Rose,2004) to conduct some studies in second language acquisition. When Goleman (1995) introduced the concept of "Emotional Intelligence", some researchers got motivated to investigate its contribution to the development of language abilities. The concept of emotional intelligence originated from social intelligence, and also emanated from Gardner's (1983) contribution to the concept. The term emotional intelligence appears to have originated with Wayne Pyne (1985). Supporting Pyne's ideas, Danciu (2010) asserted that emotional intelligence is the most important determiner of success and failure. 
An individual's capability to perform and act effectively in various cultural settings is referred to as cultural intelligence. This definition has some overlap with Schmidt and Hunter's (2000) definition of general intelligence. They defined general intelligence as the ability to learn, understand and reason the subjects accurately. Researchers in the past had a restricted view on intelligence and considered it as being effective in only academic contexts; however, nowadays, it is widely accepted among researchers that intelligence is functioning in contexts other than academic settings (Sternberg \& Detterman, 1986). Due to the interest in studying intelligence, researchers concentrated on certain domains such as cultural intelligence (Earley \& Ang, 2003), emotional intelligence (Mayer et al., 2000), social intelligence (Thorndike \& Stein, 1937), practical intelligence (Sternberg et. al., 2000), and spiritual intelligence (Amram and Dryer (2007).

Cultural intelligence deals with the concrete characteristics of globalization and puts emphasis on a particular domain-intercultural context (Earley \& Ang, 2003). Based on the general definition of general intelligence (Schmidt \& Hunter, 2000), cultural intelligence is a certain type of intelligence which is most concerned with those capabilities to understand reason and behave effectively in various cultural contexts. Based on the insights proposed by cultural intelligence, an individual can cope with cross-cultural contexts and create successful communication. Cultural intelligence is considered as a difference among individuals, which characterizes their capability to function effectively when they communicate with individuals from other nations or countries (Ang et al, 2006; Ng \& Earley, 2006). People with higher cultural intelligence could understand behavioral characteristics of other people in contact and interacts with them suitably. Therefore, cultural intelligence helps people promote a reasonable interaction with others (Triandis, 2006).

Emotional intelligence functions as a means to improve students' language learning and helps teachers to gain success in their professional career. Teachers should have an awareness of their emotions and feelings to help them solve their problems. People who have higher EQ benefit from a sense of creativity, develop a sense of plausible thinking, manage their anxiety, and establish good relationship with others. Emotional intelligence is a trigger for a person to satisfy his mental, emotional, physical, and spiritual needs, and to make a successful communication with other people (Singh, 2006). According to psychologists, emotional intelligence is different from other types of intelligence because it has a decisive role in learners' contemplation and is very significant in their academic achievement (Sharp, 2001). According to a study done by Goleman female and male participants did not show a significant difference in their emotional intelligence. However, some variations between men and women could be observed in certain aspects of emotional intelligence (1998). He further revealed that emotional intelligence caused the academic performance to improve significantly since it could help students increase their self-confidence, self-control, communication skills and collaborative work.

Social intelligence is another form of intelligence that could be of use in language education contexts. According to Albrecht (2006), social intelligence is considered as a requirement for teachers in educational settings. He believes that educational systems and teachers are recommended to respect educational regulations and people's behaviors with high social intelligence. The young students should learn good behavior, the culture and subculture and the value of collaboration to survive in this modern world. Social intelligence increases with age and experience of a person. Thorndike (1920) assumed that social intelligence develops right from birth and by the time a child begins schooling, the interactions with diverse environmental factors and the aggregate of social and cultural conditions would have a profound influence on his/her life (Jonçich, 1962). In this study, a multifaceted theory of social intelligence was used by the researcher as it facilitated the understanding of social behavior in the academic settings.

Social intelligence was originally defined as "the ability to understand and manage men and women, boys and girls, to act wisely in human relations" (Thorndike, 1920: p 229). There is some closeness and commonality between this definition and "interpersonal intelligence" proposed in Gardner's (1983) MI theory. There have been two views on social intelligence: the first is the restricted view in which the researchers view it as the knowledge of social situations, perhaps called social cognition or social marketing intelligence, as it relates to socio-psychological advertising and marketing strategies and tactics. The second view is a wide-scope view. Based on this view, social intelligence is "a person's competence to understand his or her environment optimally and react appropriately for socially successful conduct" (Babu, 2013, p.65).

Spiritual intelligence is yet another element in effective instruction. Zohar and Marshall (2000) were of the view that when the level of spiritual intelligence is high, we are in contact with our wholeness. Our personality traits reflect our inner self and we tend to be intellectual and develop proper behavior. When the level of our spiritual intelligence is low, we become caricatures of ourselves. Our feelings and emotional models are not stable and we experience difficult behavior patterns. This intelligence also increases with age and is not linked to any religion. Donahue and Benson (1995) mentioned that there are supporting findings to indicate that increased participation in spiritual activity is strongly related to a higher well-being, lower level of delinquency, misbehavior and other social problems (Compton, 2005). The spirituality theories maintain that effective education must recognize the spiritual and emotional development of the child, the significance and impact of the arts as well as a conducive education process. Such an integrated education system will enable students to connect through common emotional experiences and realize their full potential (Geula, 2004). 
Spiritual intelligence, according to Amram and Dryer (2007), provides the individuals with better well-being, lower misunderstandings and misbehaviors, and more comfortable life. According to Dincer (2007), spiritual intelligence prepares a person to develop self-esteem, wholeness, perfection, goal and ambitions. Dincer believes teachers having higher spiritual intelligence are able to help students from various age groups to experience self-respect and creativity in their life.

Students' activities, behaviors, interactions, and gestures during a class, observed, planned and monitored by the teacher, are technically referred to as classroom management (Fredrick, Deitz, Bryceland, \& Hummel, 2000). The objective is to establish a conducive classroom atmosphere which fosters effective learning and acceptable behavior (Martin, Sugarman, \& Mc Namara, 2000, p.9). To establish positive teacher-student relationships, classroom management strategies play a very important part, which in turn, could enhance the students' academic achievement and their social, emotional and behavioral performance (Wang, Haertel, \& Walberg, 1993). Improved teacher-student interaction could have a positive effect on classroom discipline by influencing students' task-related behavior (Marzano, Marzano, \& Pickering, 2003). Athanases, Christiano and Lay (1995) suggested that through establishing a social setting of trust and respect as well as modeling, the classroom climate is likely to improve the students' ability to care for others and learn more effectively.

Some studies have been done to examine the role of some of these types of intelligences on various aspects of language learning: trait emotional intelligence in academic performance and deviant behavior at school (Petrides, Frederickson, and Furnham, 2004), the influence of emotional and verbal intelligences on second language learning (Pishghadam,2007), the relationship between emotional intelligence and vocabulary learning among Iranian preuniversity EFL learners (Alavi \& Rahimi, 2011), the relationship between emotional intelligence and general mental ability and academic performance of the students (Song, Haung, Peng, Law, Wong, and Chen,2010); the relation between academic achievement and several dimensions of emotional intelligence ( Fahim \& Pishghadam, 2007); the relation between cognitive ability and academic performance and trait emotional intelligence (Petrides, Furnham, \& Frederickson. 2004); social and academic success and the overall emotional intelligence among gifted adolescents (Woitaszewski \& Aalsma,2004); the relationship between emotional intelligence and academic achievement ( Bastian, Burns, \& Nettelbeck,2005), and the relationship between EFL teachers' self-efficacy and trait emotional intelligence (Nikoopour, Amini Farsani, Tajbakhsh \& Sadat Kiaee,2012).

According to Boyatzis (2000), these types of intelligences are not fixed, but they are modifiable and can be developed. Thus, policy makers, language teachers, and material developers can increase their professional development if they are culturally, emotionally, and socially intelligent. According to Bar-on (2007), scientific observations and empirical studies are to be done to help develop educational programs to create emotionally and socially intelligent behavior among students. Bar-on (2007) believes that emotional intelligence establishes a more effective, successful, innovative, and humane community in educational system. Parents and teachers are expected to be aware of the concept of intelligences so that they could understand children's emotions and feelings respectfully, provide them with the support and dedication they need, and help them learn more skills to manage their emotions (Saarni, 2007). The aim of this study is to find out the relationship between cultural, spiritual, social, emotional intelligence and teaching effectiveness among Iranian EFL teachers.

\section{METHOD}

\section{A. Participants}

The participants of the study were Iranian EFL teachers, observers and learners. From the total number of participants (423), almost half of them (53.9\%) were female (228) and (46.1\%) were male (195). A group of 126 male and female EFL teachers $(29.8 \%$ of the whole sample) were almost randomly selected from different educational districts of Tehran. They were assessed for their emotional, cultural, spiritual and social intelligence as well as their teaching effectiveness. The teachers' gender, age, university degrees and teaching experience were taken into account to see whether they would modify the research findings or not. A group of 31 observers (7.3\% of the whole sample) participated in the study to help the researcher elicit data about the EFL teachers' teaching effectiveness in their EFL classes. They were all experienced EFL teachers who had been teaching English in various schools and language institutes at different levels. The observers had the experience of observing EFL classes before the present study. However, they were trained to use a certain observation checklist to collect data on the effective teaching of EFL teachers in their classes. The third group of participants was 266 EFL male and female learners $(62.9 \%$ of the whole sample) to whom the questionnaire of effective teaching was given and they were expected to assess their teachers' effective teaching in their own classes. Since teaching effectiveness might not have been perfectly assessed through EFL teachers' self-report questionnaire, the researcher went for triangulated data; that is, the data elicited from EFL teachers, observers and learners.

\section{B. Instruments}

Teaching Effectiveness Questionnaire: Teacher Questionnaire, developed and validated by Moafian \& Pishghadam (2009), was used to investigate the EFL teachers' teaching effectiveness. The psychometric characteristics of the questionnaire were acceptable; that is, the total reliability based on Cronbach alpha was 0.94 and the reliability index 
for each factor was also acceptable. The construct validity of the questionnaire was proved to be acceptable; that is, a principled axis factoring extracted twelve factors from the questionnaire, and these factors had special amount more than one and accounted for $\% 48$ of the variance, and variable commonalities were all more than $\% 30$. The questionnaire consisted of different parts measuring the twelve sub-constructs of effective teaching. There were 49 items arranged in a 5-likert scale closed-questionnaire format. Secondly, the Learner Questionnaire was used to investigate the students ' assessment of their EFL teachers' teaching effectiveness. This questionnaire consisted of the same sub-constructs of the Teachers' Questionnaire, to enable the researcher to correlate the two sets of data together to find out any sort of relation. Thirdly, the researcher utilized an observation checklist to assess the performance of EFL teachers in their classes. Thus, thirty one EFL teachers' classes were carefully observed based on the observation checklist which shared almost all items of the two aforementioned questionnaires. All the three research tools were checked for their reliability indexes within the new distribution.

Trait Emotional Intelligence Questionnaire: The second instrument was a Trait Emotional Intelligence Questionnaire (TEIQue), which consisted of 30 items in a 5-likert scale. This questionnaire was based on the long form of the TEIQue (Petrides \& Furnham, 2001), which was designed to measure trait emotional intelligence. TEIQue was in the closed form, Likert scale, which provided 5 choices for the participants to select. The choices were from completely disagree (1), disagree (2), no idea (3), agree (4), and completely agree (5). TEIQue has four underlying sub-constructs: emotionality, self-control, well-being, sociability and global trait EI. The reliability index computed for TEIQue was 0.85 which was quite reasonable.

Cultural Intelligence Scale (CQS): As the third research tool, the researchers used Cultural Intelligence Scale (CQS) for measuring the EFL teachers' cultural intelligence. Three perspectives on CQ measurement have been dominant within the CQ research. According to Earley and Ang (2003), CQ consists of three key structural components: cognitive, motivational, and behavioral. Another perspective on the analysis of CQ, advanced by Thomas and Inkson (2004), involves three major interlocking components of cultural knowledge, mindfulness, and behavioral skills. Finally, Ang, Van Dyne, Koh, Ng, Templer, Tay and Chandrasekar (2007) proposed a four-factor model of CQ based on Earley and Ang's (2003) conceptualization, comprised of cognitive, metacognitive, motivational, and behavioral dimensions. There were 19 items arranged to measure the four sub-constructs of the cultural intelligence: cognitive, metacognitive, motivational, and behavioral dimensions. The reliability coefficient for was 0.713 , which was appropriate for the present study.

Social Intelligence Scale: A scale for measuring social intelligence, the Troms $\varnothing$ Social Intelligence Scale (TSIS) designed by Silvera, Martinussen and Dahl (2001) was used for the study. The researcher investigated the questionnaire to be construct valid. The Factor Analysis finally led to the inclusion of 21 items in the questionnaire, seven of which represented each of the three factors. The three sub-constructs were Social Information Processing, Social Skills, and Social Awareness. The reliability coefficient of the social intelligence questionnaire proved to be 0.699.

Integrated Spiritual Intelligence Scale (ISIS): To address the limitations of previous measures of spiritual intelligence, Amram and Dryer (2007) developed the Integrated Spiritual Intelligence Scale (ISIS). The instrument used in the study was a self-reporting questionnaire which had seven domains, 22 specific capabilities, and 83 items, arranged in the sixpoint Likert scale. The options were "rarely or almost never; very infrequently; somewhat infrequently, somewhat often; very frequently; and always or almost always". The internal consistency of the whole questionnaire was high (Cronbach Alpha $=0.97)$. Also, the internal consistency of the domain scales was high; ranging from 0.84 to 0.95 , with a mean value of 0.89. The Cronbach alpha values for the each of the domains are (i) Consciousness (0.84); (ii) Grace (0.91); (iii) Meaning (0.86); (iv) Truth (0.90), (v) Wholeness (0.88); (vi) Presence (0.91); and (vii) Inner directedness, (0.86). The ISIS demonstrated acceptable test-retest reliability (Pearson $r=0.77)$.

\section{Procedure}

The researchers went through different phases: at first, they prepared the five questionnaires and checked for their reliability. Since each of the five research questionnaires had already been validated in the previous studies, the researchers did not check for their construct validity, but computed their reliability indexes for the new distribution. As the second phase, the questionnaires were translated into Persian to guarantee the participants' understanding. Then, each questionnaire was administered to the participants in a separate session to measure the variables under the study respectively. Before distributing each questionnaire, the researchers provided the participants with a briefing explanation about the nature of the questionnaire. Having collected the data as the last phase, the researchers went through the process of data entry and data analysis.

\section{RESULTS}

The study revealed that among EFL teachers, there was a significant correlation between teaching effectiveness and TEQ, but the correlation between teaching effectiveness and the three other types of intelligence (SQ, CQ, \& SPQ) was not statistically significant (Table 1). 
TABLE 1.

CORRELATION BETWEEN TEACHING EFFECTIVENESS AND INTELLIGENCES

\begin{tabular}{llllll}
\hline & & CQ & SQ & TEQ & SPQ \\
\hline TE & Pearson Correlation & .069 & .037 & $.237^{* *}$ & .149 \\
& Sig. (2-tailed) & .443 & .684 & .008 & .095 \\
& $\mathrm{~N}$ & 126 & 126 & 126 & 126 \\
\hline
\end{tabular}

The three groups of participants (teachers, observers, and learners) showed a significant difference in their perception of effective teaching (Table 2).

TABLE 2.

ANOVA FOR TEACHING EFFECTIVENESS BY GROUPS

\begin{tabular}{llllll}
\hline \multicolumn{7}{c}{ Sum of Squares } & df & Mean Square & F & Sig. \\
\hline Between Groups & 141042.81 & 2 & 70521.40 & 461.175 & .000 \\
Within Groups & 64225.10 & 420 & 152.91 & & \\
Total & 205267.91 & 422 & & & \\
\hline
\end{tabular}

It seems that effective teaching is a controversial issue since it is perceived differently by three groups involved directly in teaching/learning process. A post hoc comparison (Table 3) shows that observers have a significant difference in their perception of effective teaching in comparison with EFL teachers and learners.

TABLE 3.

MULTIPLE COMPARISONS IN TEACHING EFFECTIVENESS BY GROUPS

\begin{tabular}{|c|c|c|c|c|c|c|}
\hline \multirow[b]{2}{*}{ (I) group } & \multirow[b]{2}{*}{$(\mathrm{J})$ group } & \multirow[b]{2}{*}{ Mean Difference } & \multirow[b]{2}{*}{ Std. Error } & \multirow[b]{2}{*}{ Sig. } & \multicolumn{2}{|c|}{$95 \%$ Confidence Interval } \\
\hline & & & & & Lower Bound & Upper Bound \\
\hline EFL teachers & EFL learners & 1.971 & 1.337 & .141 & -.66 & 4.60 \\
\hline \multirow{3}{*}{ EFL learners } & EFL observers & $71.323^{*}$ & 2.479 & .000 & 66.45 & 76.20 \\
\hline & EFL teachers & -1.971 & 1.337 & .141 & -4.60 & .66 \\
\hline & EFL observers & $69.352^{*}$ & 2.347 & .000 & 64.74 & 73.97 \\
\hline \multirow{2}{*}{$\begin{array}{l}\text { EFL } \\
\text { observers }\end{array}$} & EFL teachers & $-71.323^{*}$ & 2.479 & .000 & -76.20 & -66.45 \\
\hline & EFL learners & $-69.352^{*}$ & 2.347 & .000 & -73.97 & -64.74 \\
\hline
\end{tabular}

Since the four types of intelligences have been measured based on self-reporting questionnaires, a correlational analysis was employed to see whether these four types of intelligences are correlated. As the results show (Table 4), there is a significant correlation among all four types. Although the correlation coefficients in between are not high, they are significant. The highest extent is 0.468 , which is the correlation between Trait Emotional Intelligence (TEQ) and Spiritual Intelligence (SPQ), and the lowest extent of correlation is 0.201 , which is the correlation between Cultural Intelligence (CQ) and Trait Emotional Intelligence (TEQ). The level of significance has been marked with one asterisk (0.05 level) and with two asterisks (0.01 level) in the data.

TABLE 4.

CORRELATIONS BETWEEN TYPES OF INTELLIGENCES

\begin{tabular}{|c|c|c|c|c|c|}
\hline & & CQ & SQ & TEQ & SPQ \\
\hline \multirow[t]{3}{*}{ CQ } & Pearson Correlation & 1 & $.240^{* *}$ & $.201^{*}$ & $.462^{* *}$ \\
\hline & Sig. (2-tailed) & & .007 & .024 & .000 \\
\hline & $\mathrm{N}$ & 126 & 126 & 126 & 126 \\
\hline \multirow[t]{3}{*}{ SQ } & Pearson Correlation & $.240^{* *}$ & 1 & $.230^{* *}$ & $.402^{* *}$ \\
\hline & Sig. (2-tailed) & .007 & & .010 & .000 \\
\hline & $\mathrm{N}$ & 126 & 126 & 126 & 126 \\
\hline \multirow[t]{3}{*}{ TEQ } & Pearson Correlation & $.201^{*}$ & $.230^{* *}$ & 1 & $.468^{* *}$ \\
\hline & Sig. (2-tailed) & .024 & .010 & & .060 \\
\hline & $\mathrm{N}$ & 126 & 126 & 126 & 126 \\
\hline \multirow[t]{3}{*}{ SPQ } & Pearson Correlation & $.462^{* *}$ & $.402^{* *}$ & $.468^{* *}$ & 1 \\
\hline & Sig. (2-tailed) & .000 & .000 & .060 & \\
\hline & $\mathrm{N}$ & 126 & 126 & 126 & 126 \\
\hline
\end{tabular}

In further analysis, gender made a significant difference in TEQ, but female and male EFL teachers did not show a significant difference in their CQ, SQ, SPQ and effective teaching. University degree caused a significant difference in SQ and TEQ, but not in TE, SPQ and CQ. However, teaching experience and age made a significant difference in all four variables under the study (Table 5-8, in Appendix) 


\section{DISCUSSION}

A closer look at the interrelationships of four types of intelligences showed that there was a moderate positive correlation between them. Cultural intelligence has correlation with SQ, TEQ, and SPQ with a correlational coefficient of $0.240,0.201$, and 0.462 respectively. Social intelligence has correlation with TEQ (0.230), and a higher correlation with SPQ (0.402), and finally the correlation between SPQ and TEQ was 0.468 . The highest coefficient was 0.462 and the lowest one was 0.201 ; however, all coefficients were statistically significant. The relationships among these intelligences are quite meaningful and can be interpreted. It seems that these types of intelligences have something in common, which indicates the extent of their correlation. The EFL teachers have shown moderate but significant correlation in all their intelligences, which signifies compatibility and/or commonality of these intelligences.

Contrary to Goleman (1998), who stated that there are no perceptible gender differences in emotional intelligence, while gender is taken into account, EFL teachers indicated to have a significant difference in their trait emotional intelligence; however, gender did not make any significant difference in their spiritual, cultural and social intelligence. Therefore, female and male EFL teachers are emotionally different, whereas they are homogeneous in their social, spiritual and cultural intelligence. This difference might be due to the nature of female EFL teachers, who are more sensitive, more flexible, or even less serious in their profession. A good point in gender analysis was the equality in teaching effectiveness among EFL female and male teachers. Hence, gender as a moderator variable is not a determining factor to cause any discrepancy in EFL teachers' performance in their classes.

The analysis of variance on the data showed that university degree did not make a significant difference between Associate Diploma, BA and MA holders in their spiritual and cultural intelligence. However, it did make a significant difference among the different groups of teachers (Associate Diploma, BA and MA holders) in social and trait emotional intelligence. A Post Hoc analysis showed that BA and MA holders had a significant difference in their social intelligence. Also, the significant difference in trait emotional intelligence was between MA holders and the other two groups. It was obvious that university education was not a determining factor to cause such differences. What can be accounted for the EFL teachers' effectiveness in their real life EFL instructional contexts cannot be merely attributed to the teachers' university degree. As it has been also found, some studies have been done to investigate the characteristics of effective teaching. Some scholars included participants in their studies who characterized effective teachers, for instance they selected good students and weaker students (Koutsoulis, 2003), male and female students (Witcher et al., 2001; Minor, Onwuegbuzie \& Witcher, 2002), teachers and students (Lang, McKee \& Conner, 1993), and students with different majors (Check, 1986) as subjects of their study.

The EFL teachers' teaching experience showed a significant difference in all five variables under the study. The findings of the present study were in agreement with those of previous researchers in that teaching effectiveness increases greatly over the years of teaching practice (Chidolue 1996; Rice 2003; Murnane, Singer, Willett, Kemple \& Olsen, 1991; Leigh 2007; Needels 1991). It was obvious that teaching experience is a crucial factor since it made a significant difference in EFL teachers' TEQ, CQ, SPQ and SQ. The teaching experience does help increase their professional development and accordingly, their teaching effectiveness. It is also interesting to mention that age made a significant difference in the EFL teachers' four types of intelligences: social, cultural, spiritual and emotional intelligence as well as their teaching effectiveness.

Considerable attention has been devoted by the researchers to the quality of teaching so that it could improve the quality of education (Ellett \& Teddlie, 2003) and to improve the educational system (Schulte, Slate, \& Onwuegbuzie, 2008). Therefore, many scholars across different cultures have attempted to investigate the characteristics of effective teaching (Martin, 2007) and disciplines of study (Park \& Lee, 2006). The two main issues which characterize the realm of EFL professional development are describing the necessary characteristics of an effective teacher and developing good teachers in practice (Korthagen, 2004).

In the literature, "teaching effectiveness is not a simple construct" (Bailey, 2006, p.213); that is, it is a complicated concept which is being influenced by many variables, such as teachers' personal characteristics (Tickle, 1999), content knowledge (Mewborn, 2001), caring behavior (Cotton, 2000), and the culture of teaching environment (Schulte et al., 2008). Not only is an effective EFL teacher required to develop reasonable teaching competence comprising of English language proficiency, pedagogical content knowledge, professional development, and contextual knowledge, but s/he is also expected to be socially, culturally, emotionally, and spiritually intelligent enough to act effectively and plausibly in various settings.

The study done by Adamson and Davison (2003) showed that parental beliefs and education can influence students' perception of effective teaching. It was also found by Opdenakker and Van Damme (2006) that the characteristics of the students' families, parents' involvement in schooling, their support, and their interest in children's academic life affect the effectiveness of class, the learning climate and the teacher-student relationship. Due to the multifaceted nature of teacher development, various studies surveyed the function of "educational context including the array of cultural, social, racial, and other groups to which students and teachers belong" (Kanu 2005, p. 495) in enhancing the teachers' teaching effectiveness. Several studies have shown that developing professional identity (Flores \& Day 2006), teachers' self-efficacy and professional development (Fisher \& Fraser 1991), and perceived professional certainty (Munthe 2003) support the fact that teacher variables influence the school environment and students' academic achievement. 
Several studies attempted to investigate factors in the school context such as teachers' affiliation and professional interest (Webster \& Fisher 2003), and some other studies concentrated on "the context beyond school" (Elizabeth et al. 2008, p. 631) such as teacher's intelligences and parents' support to find out their influence on teachers' effective instructional practice. Other teacher-related variables such as teacher motivation, job satisfaction, job dedication, and job stress as well as some contextual factors such as conflict with workmates, lack of staff freedom and autonomy, student misbehavior and too much work (Kokkinos 2007; Malach-Pines 2005) can also affect the teaching effectiveness of EFL teachers in their classes. The report of these studies justifies the implementation of the present study since the EFL teachers' social, emotional, spiritual and cultural intelligence may influence the teaching effectiveness.

\section{APPENDIX}

TABLE 5.

ANOVA FOR TE AND TYPES OF INTELLIGENCES BY GENDER

\begin{tabular}{|c|c|c|c|c|c|c|}
\hline & & & & & & \\
\hline & & sum oi squales & D1 & viean square & 1 & Sig. \\
\hline TE & Within Groups & 204650.39 & 421 & 486.10 & & \\
\hline \multirow[t]{2}{*}{ CQ } & Between Groups & 334.71 & 1 & 334.71 & 3.155 & .078 \\
\hline & Within Groups & 13156.50 & 124 & 106.10 & & \\
\hline \multirow[t]{3}{*}{ SQ } & Between Groups & 356.57 & 1 & 356.57 & 3.126 & .080 \\
\hline & Within Groups & 14144.92 & 124 & 114.07 & & \\
\hline & Total & 14501.50 & 125 & & & \\
\hline TEQ & Between Groups & 521.96 & 1 & 521.96 & 36.630 & .000 \\
\hline \multirow{2}{*}{ SPQ } & Within Groups & 17146.09 & 124 & 138.27 & & \\
\hline & Total & 17148.85 & 125 & & & \\
\hline
\end{tabular}

TABLE 6.

ANOVA FOR TE AND TYPES OF INTELLIGENCES BY AGE

\begin{tabular}{|c|c|c|c|c|c|c|}
\hline & & Sum of Squares & df & Mean Square & $\mathrm{F}$ & Sig. \\
\hline \multirow[t]{3}{*}{ TE } & Between Groups & 48417.91 & 32 & 1513.06 & 3.762 & .000 \\
\hline & Within Groups & 156850.02 & 390 & 402.17 & & \\
\hline & Total & 205267.91 & 422 & & & \\
\hline \multirow[t]{3}{*}{ CQ } & Between Groups & 5264.31 & 21 & 250.68 & 3.169 & .000 \\
\hline & Within Groups & 8226.9 & 104 & 79.1 & & \\
\hline & Total & 13491.21 & 125 & & & \\
\hline \multirow[t]{3}{*}{ SQ } & Between Groups & 7457.1 & 21 & 355.1 & 5.243 & .000 \\
\hline & Within Groups & 7044.4 & 104 & 67.73 & & \\
\hline & Total & 14501.5 & 125 & & & \\
\hline \multirow[t]{3}{*}{ TEQ } & Between Groups & 1303.32 & 21 & 62.06 & 6.549 & .000 \\
\hline & Within Groups & 985.6 & 104 & 9.47 & & \\
\hline & Total & 2288.92 & 125 & & & \\
\hline \multirow[t]{3}{*}{ SPQ } & Between Groups & 8814.75 & 21 & 419.75 & 5.238 & .000 \\
\hline & Within Groups & 8334.1 & 104 & 80.13 & & \\
\hline & Total & 17148.85 & 125 & & & \\
\hline
\end{tabular}


TABLE 7.

ANOVA FOR TE AND TYPES OF INTELLIGENCES BY UNIVERSITY DEGREE

\begin{tabular}{|c|c|c|c|c|c|c|}
\hline & & Sum of Squares & df & Mean Square & $\mathrm{F}$ & Sig. \\
\hline \multirow[t]{3}{*}{ TE } & Between Groups & 477.14 & 2 & 238.57 & .309 & .734 \\
\hline & Within Groups & 168287.65 & 218 & 771.96 & & \\
\hline & Total & 168764.80 & 220 & & & \\
\hline \multirow[t]{3}{*}{ CQ } & Between Groups & .214 & 2 & .17 & .001 & .999 \\
\hline & Within Groups & 13491.00 & 123 & 109.68 & & \\
\hline & Total & 13491.21 & 125 & & & \\
\hline \multirow[t]{3}{*}{ SQ } & Between Groups & 2284.90 & 2 & 1142.45 & 11.503 & .000 \\
\hline & Within Groups & 12216.59 & 123 & 99.32 & & \\
\hline & Total & 14501.50 & 125 & & & \\
\hline \multirow[t]{3}{*}{ TEQ } & Between Groups & 258.40 & 2 & 129.20 & 7.827 & .001 \\
\hline & Within Groups & 2030.52 & 123 & 16.50 & & \\
\hline & Total & 2288.92 & 125 & & & \\
\hline \multirow[t]{3}{*}{ SPQ } & Between Groups & 13.46 & 2 & 6.73 & .048 & .953 \\
\hline & Within Groups & 17135.39 & 123 & 139.31 & & \\
\hline & Total & 17148.85 & 125 & & & \\
\hline
\end{tabular}

TABLE 8.

ANOVA FOR TE \& INTELLIGENCES BY TEACHING EXPERIENCE

\begin{tabular}{|c|c|c|c|c|c|c|}
\hline & & Sum of Squares & df & Mean Square & $\mathrm{F}$ & Sig. \\
\hline \multirow[t]{3}{*}{ TE } & Between Groups & 61341.03 & 24 & 2555.87 & 4.265 & .000 \\
\hline & Within Groups & 106666.64 & 178 & 599.25 & & \\
\hline & Total & 168007.68 & 202 & & & \\
\hline \multirow[t]{3}{*}{ CQ } & Between Groups & 7728.56 & 20 & 386.42 & 7.041 & .000 \\
\hline & Within Groups & 5762.65 & 105 & 54.88 & & \\
\hline & Total & 13491.21 & 125 & & & \\
\hline \multirow[t]{3}{*}{ SQ } & Between Groups & 7930.01 & 20 & 396.5 & 6.335 & .000 \\
\hline & Within Groups & 6571.50 & 105 & 62.58 & & \\
\hline & Total & 14501.50 & 125 & & & \\
\hline \multirow[t]{3}{*}{ TEQ } & Between Groups & 1374.32 & 20 & 68.71 & 7.889 & .000 \\
\hline & Within Groups & 914.60 & 105 & 8.71 & & \\
\hline & Total & 2288.92 & 125 & & & \\
\hline \multirow[t]{3}{*}{ SP } & Between Groups & 9564.07 & 20 & 478.2 & 6.620 & .000 \\
\hline & Within Groups & 7584.85 & 105 & 72.23 & & \\
\hline & Total & 17148.85 & 125 & & & \\
\hline
\end{tabular}

\section{REFERENCES}

[1] Adamson, B., \& Davison, C. (2003). Innovation in English language teaching in Hong Kong primary schools: One step forward, two steps sideways? Prospect, 18(1), 27-41.

[2] Alavi, S.M., \& Rahimi, Z. (2011). On the relationship between emotional intelligence and vocabulary learning among Iranian pre-university EFL learners. Journal of English Studies, 1(3), 17-25.

[3] Albrecht, K. (2006). Social Intelligence: The New science of Success. San Francisco, CA: Jossey-Bass.

[4] Amram, Y. \& Dryer, C. (2007). The Development and Preliminary Validation of the Integrated Spiritual Intelligence Scale (ISIS). Palo Alto, CA: Institute of Transpersonal Psychology Working Paper.

[5] Ang, S., Van Dyne, L., \& Koh, C. (2006). Personality correlates of the four-factor model of cultural intelligence. Group and Organization Management, 31, 100-123.

[6] Ang, S., Van Dyne, L., Koh, C., Ng, K., Templer, K.J., Tay, C., \& Chandrasekar, N.A. (2007). Cultural intelligence: Its measurement and effects on cultural judgment and decision making, cultural adaptation, and task performance. Management and Organization Review, 3, 335-371.

[7] Armstrong, T. (1995). Multiple intelligences in the classroom. Alexandaria, VA: ASCD.

[8] Athanases, S. Z., Christiano, D., \& Lay, E. (1995). Fostering Empathy and Finding Common Ground in Multiethnic Classes. English Journal, 84(3), 26-34.

[9] Babu M, S. (2013). Social Intelligence and Aggressive Behavior in relation to Classroom Climate in relation to Classroom Climate among Upper Primary School Students of Delhi and Kerala. Unpublished Ph D Thesis. Faculty of Education, Jamia Millia Islamia, India

[10] Bailey, K.M.(2006). Language teacher supervision: a case-based approach. Cambridge: Cambridge University Press.

[11] Bar-on, R. (2007). How important is it to educate people to be emotionally intelligent, and can it be done? In R. Bar-on, J.G. Maree, \& M.J. Elias (Eds.), Educating people to be emotionally intelligent (pp.1-14). London: Praegar. 
[12] Bastian, V.A., Burns, N.R., \& Nettelbeck, T. (2005).Emotional intelligence predicts life skills, but not as well as personality and cognitive abilities. Personality and Individual Differences, 39, $1135-1145$.

[13] Bernhardt, E., \& Jammadou, J. (1987). A decade of research in foreign language teacher education. Modern Language Journal, 71, 289-99.

[14] Boyatzis, R.E. (2000). Developing emotional intelligence. In C.Cherniss, R.E., Boyatzis \& M. Elias (Eds.), Development in emotional intelligence (pp.1-35). San-Francisco: Jossey-Bass.

[15] Brosh, H. (1996). Perceived characteristics of the effective language teacher. Foreign Language Annuals, 29(2), $125-138$.

[16] Check, J. (1986). Positive trace of the effective teacher- Negative trace of the ineffective one. Education, 106; 326-334.

[17] Chen, J-Q., \& Gardner, H. (2005). Assessment based on multiple intelligence theory. In D.P. Flanagan (Ed.), Contemporary intellectual assessment: Theories, tests, and issues (77-102). New York: Guilford Press.

[18] Chidolue, M. E. (1996). The relationship between teacher characteristics, learning environment and student achievement and attitude. Studies in Educational Evaluation, 22, 263-74.

[19] Compton, W. C. (2005). Introduction to Positive Psychology. Belmont, CA: Wadsworth.

[20] Cotton, K, (2000). The schooling practices that matter most. Alexandria, VA: Association for Supervision and Curriculum Development.

[21] Danciu, E.L. (2010). Methods of developing children's emotional intelligence. Procedia Social and Behavioral Sciences. 5, 2227-2233.

[22] Demmon-Berger, D. (1986). Effective teaching: Observations from research. Arlington, VA: American Association of School Administrators. (ERIC Eric Document Reproduction Service No. 274 087).

[23] Dincer, M. K. (2007). Educators Role as Spiritually Intelligent Leaders in Educational Institutions. International Journal of Human Sciences, 4 (1). Accessed on August 23, 2009 from www.insanBilimleri.com/en.

[24] Donahue, M. J., \& Benson, P. L. (1995). Religion and the Well-Being of Adolescents. Journal of Social Issues, 51(2), 145-160.

[25] Earley, C., \& Ang, S. (2003). Cultural intelligence: Individual interactions across cultures. Stanford, CA: Stanford Business Books.

[26] Elizabeth, C., May, C., \& Chee, P. (2008). Building a model to define the concept of teacher success in Hong Kong. Teaching and Teacher Education, 24(3), 623-634.

[27] Ellett, C.D., \& Teddlie, C. (2003). Teacher evaluation, teacher effectiveness, and school effectiveness: Perspectives from US. Journal of Personnel Evaluation in Education, 17(1), 101-128.

[28] Fahim, M., \& Pishghadam, R. (2007). On the role of emotional, psychometrics and verbal intelligences in the academic achievement of university students majoring in English language. Asian EFL Journal, 9(4), 240-253.

[29] Fisher, D. L., \& Fraser, B. J. (1991). Validity and use of the school level environment. Journal of Classroom Interaction, 26(2), $13-18$.

[30] Flores, M. A., \& Day, C. (2006). Contexts which shape and reshape new teachers' identities: A multi-perspective study. Teaching and Teacher Education, 22(2), 219-232.

[31] Fredrick, L. D., Deitz, S. M., Bryceland, J. A., \& Hummel, J. H. (2000). Behavior Analysis, Education, and Effective Schooling. Reno, NV: Context Press.

[32] Freeman, D., \& Johnson, K. (1998). Reconceptualizing the knowledge-base of language teacher education. TESOL Quarterly, $32,397-417$.

[33] Gardner, H. (1983). Frames of mind: The theory of multiple intelligences. New York: Basic Books.

[34] Geula, K. (2004). Emotional Intelligence and Spiritual Development. Paper Presented at The Forum for Integrated Education and Educational Reform, Santa Cruz, CA, October 28-30. Accessed on June 2, 2009 from http://chiron.valdosta.edu/whuitt/CGIE/guela.pdf.

[35] Goleman, D. (1996). Emotional Intelligence. London: Bloomsbury.

[36] Goleman, D. (1995). Emotional intelligence: Why it can matter more than IQ. New York: Bantam Books.

[37] Goleman,D. (1998).Working with emotional intelligence. New York: Bantam Books.

[38] Joncich, G. M. (1962). Science: Touchstone for a New Age in Education. In G. M. Jonçich (ed.), Psychology and the Science of Education: Selected Writings of Edward L. Thorndike. New York: Columbia Teachers College Press.

[39] Kanu, Y. (2005). Tensions and dilemmas of cross-cultural transfer of knowledge: Post- structural/postcolonial reflections on an innovative teacher education in Pakistan. International Journal of Educational Development, 25(5), 493-513.

[40] Kokkinos, C. M. (2007). Job stressors, personality and burnout in primary school teachers. British Journal of Educational Psychology, 77(1), 229-243.

[41] Korthagen, F.A.J. (2004). In search of the essence of a good teacher: Towards a more holistic approach in teacher education. Teaching and Teacher Education, 20(1),77-97.

[42] Koutsoulis, M. (2003). The characteristics of the effective teacher in Cyprus public high school: The students' perspective. Arlington, VA: American Association of School Administrators. (ERIC Eric Document Reproduction Service No. 478 761).

[43] Lafayette, R. (1993). Subject-matter content: What every foreign language teacher needs to know. In G. Guntermann (Ed.), Developing language teachers for a changing world (pp. 125-157). Lincolnwood, IL: National Textbook Company.

[44] Lang, H., McKee, B., \& Conner, K. (1993). Characteristics of effective teachers: A descriptive study of the perceptions of faculty and deaf college students. American Annals of the Deaf, 138, 252-259.

[45] Leigh, A. (2007). Estimating teacher effectiveness from two-year changes in students' test scores. Research School of Economics, Australian National University, ACT0200, Australia. Available at http://econrsss.anu.edu.au/ aleigh/pdf/TQPanel.pdf. 2009 Elsevier Ltd. All rights Reserved. Doi: 10.1016/j.econedurev.2009.10.010.

[46] Lowman, J. (1996). Characteristics of exemplary teachers. Gi-Pyo Park, Hyo-Woong Lee.

[47] Malach-Pines, A. (2005). The burnout measure, short version. International Journal of Stress Management, 12(1), 78-88.

[48] Martin, D.B. (2007). Beyond missionaries or cannibals: Who should teach mathematics to African American children? The High School Journal, 91(1), 6-28. 
[49] Martin, J., Sugarman, J., \& McNamara, J. (2000). Models of Classroom Management: Principles, Practices and Critical Considerations. Calgary: Detselig.

[50] Marzano, R. J., Marzano, J. S., \& Pickering, D. (2003). Classroom Management That Works: Research-Based Strategies for Every Teacher. Alexandria, VA: Association for Supervision and Curriculum Development

[51] Mayer, J. D.,Caruso, R. R., \& Salovey, P. (2000), "Emotional intelligence meets traditional standards for an intelligence". Intelligence, Vol. 27, PP. 267-298.

[52] McMahon, S.D., \& Rose, D.S. (2004). Multiple intelligences and reading achievement: An examination of the inventory of multiple intelligences. The Journal of experimental Education, 73 (1), 41-52.

[53] Mewborn,D.( 2001). Teachers' content knowledge, teacher preparation, and their effect on the preparation of elementary teachers in the United States. Mathematics Education Research Journal, 3, 28-36.

[54] Minor, L., Onwuegbuzie, A., \& Witcher, A. (2002). Preservice teachers' educational beliefs and their perceptions of characteristics of effective teachers. The Journal of Educational Research, 96, 116-127.

[55] Moafian, F. \& Pishghadam, R. (2009). Preparing and investigating the construct validity of a questionnaire for EFL teachers teaching effectiveness. Journal of Foreign Languages, 54, 140-142.

[56] Mollica, A., \& Nuessel, F. (1997). The good language learner and the good language teacher: A review of the literature. Mosaic 4, 1-16.

[57] Munthe, E. (2003). Teachers' workplace and professional certainty. Teaching and Teacher Education, 19(8), 801-813.

[58] Murnane, R., Singer, J., Willett, J., Kemple, J., \& Olsen, R. (1991). Who will teach? Policies that matter. Cambridge, MA: Harvard University Press.

[59] Needels, M. C. (1991). Comparison of student, first-year, and experienced teachers' interpretations of a first-grade lesson. Teaching and Teacher Education, 7(3), 269-278.

[60] Ng, K. Y., \& Earley, P.C. (2006). Culture and intelligence: old constructs, new frontiers. Group and Organization Management, 31, 4-19.

[61] Nikoopor, J., Amini Farsani, M., Tajbakhsh, M. \& Sadat Kiaee, H. (2012). The relationship between trait emotional intelligence and self-efficacy among Iranian EFL teachers. Journal of Language Teaching and Research, 3(6), 1165-1174.

[62] Opdenakker, M., \& Van Damme, J. (2006). Teacher characteristics and teaching styles as effectiveness enhancing factors of classroom practice. Teaching and Teacher Education, 22(1), 1-21.

[63] Park,G.P., \& Lee, H.W.( 2006). Characteristics of effective English teachers perceived by high school teachers and students in Korea. Asian Pacific Education Review, 7(2), 1-19.

[64] Payne,W. L. (1986). A study of emotion, developing emotional intelligence: self-integration; relating to fear, pain, and desire. Dissertation Abstracts International, 47, 203A.

[65] Petrides, K.V. \& Furnham, A. (2001). Trait emotional intelligence: Psychometric investigation with reference to established trait taxonomies. European Journal of Personality, 15, 425-448.

[66] Petrides, K.V., Frederickson, N., \& Furnham,A. (2004). The role of trait emotional intelligence in academic performance deviant behavior at school. Personality and Individual Differences, 36, 277-293.

[67] Petrides,K.V., Furnham,A. \& Frederickson, N.( 2004). Emotional intelligence. The Psychologist, 17(10), 574-577.

[68] Pishghadam, R. (2007). On the influence of emotional and verbal intelligence on second language learning. Unpublished doctoral dissertation, Allameh Tabataba'ii University, Tehran, Iran.

[69] Rice, J. K. (2003). Teacher quality: Understanding the effectiveness of teacher attributes. Washington: Economic Policy Institute.

[70] Saarni, C.(2007). The development of emotional competence: Pathways for helping children to become emotionally intelligent. In R.Bar-On, J.G. Maree, \& M.J.Elias (Eds.), Educating people to be emotionally intelligent (pp. 15-35).

[71] Schmidt, F. L., \& Hunter, J. E. (2000). "Select on intelligence", In E. A. Locke (Ed.), The Blackwell handbook of organizational principles: $3-14$. Oxford: Blackwell.

[72] Schulte, D.P., Slate, J.R. \& Onwuegbuzie, A.J. (2008). Effective high school teachers: A mixed investigation. International Journal of Educational Research, 47(6), 351-361.

[73] Schulz, R. (2000). Foreign language teacher development: MLJ perspectives-1916-1999. Modern Language Journal, 84, 495522.

[74] Sharp, P. (2001). Nurturing Emotional Lliteracy: A Practical Guide for Teachers, Parents, and Those in the Caring Professions. London: David Fulton Publishers.

[75] Silvera, D., Martinussen, M., \& Dahl, T. I. (2001). The Troms $\varnothing$ Social Intelligence Scale: A Self Report Measure of Social Intelligence. Scandinavian Journal of Psychology, 42(4), 313-319.

[76] Singh, D. (2006). Emotional intelligence at work: A Professional Guide. New Delhi: Sage Publications Pvt. Ltd.

[77] Song, L. J., Haung,G., Peng,K.Z., Law,K.S., Wong, C., \& Chen, Z. (2010). The differential effects of general mental ability and emotional intelligence on academic performance and social interactions. Intelligence, 38, 137-143.

[78] Sternberg, R. J., Forsythe, G. B., Hedlund, J., Horvath, J. A., Wagner, R. K.,Williams, W. M., Snook, S., \& Grigorenko, E. L. (2000). "Practical intelligence in everyday life". New York: Cambridge University Press.

[79] Sternberg, R.J., \& Detterman, D.K. (1986). What is intelligence? Contemporary viewpoints on its nature and definition. Norwood, NJ: Ablex.

[80] Thomas, D., \& Inkson, K. (2004). Cultural intelligence: People skills for global business. San Francisco, CA: Berrett-Koehler Publishers.

[81] Thorndike, E.L. (1920). Intelligence and its use. Harper's Magazine, 140, 227-235.

[82] Thorndike, R., \& Stein, S. (1937). "An evaluation of the attempts to measure social intelligence", Psychological Bulletin, 34: $275-285$.

[83] Tickle, L. (1999). Teacher self- appraisal and appraisal of self. In R. P. Lipka \& T.M. Brinthaupt (Eds.), The role of self in teacher development (pp.121-141).

[84] Triandis, H.C. (2006). Cultural intelligence in organizations. Group and Organization Management, 31, $20-26$. 
[85] Vélez-Rendn, G. (2002). Second language teacher education: A review of the literature. Foreign Language Annals, 35, $457-467$.

[86] Wang, M. C., Haertel, G. D., \& Walberg, H. J. (1993). Toward a Knowledge Base for School Learning. Review of Educational Research, 63(3), 249 - 294.

[87] Webster, B. J., \& Fisher, D. L. (2003). School level environment and student outcomes in mathematics. Learning Environment Research, 6(3), 309-326.

[88] Witcher, A., Onwuegbuzie, A., \& Minor, L. (2001). Characteristics of effective teachers: Perceptions of preservice teachers. Research in the Schools, 8, 45-57.

[89] Woitaszewski, S. A., \& Aalsma, M. (2004). The contribution of emotional intelligence to the social and academic success of gifted adolescents as measured by the multifactor emotional intelligence scale: Adolescent version. Roeper Review, 27(1), 1025.

[90] Zohar, D. \& Marshall, I. (2000). SQ Spiritual Intelligence: The Ultimate Intelligence. London: Bloomsbury.

Jahanbakhsh Nikoopour is an assistant professor in Applied Linguistics at Azad University, Tehran North Branch. He was born in Tehran in 1966. He finished his BA studies in TESOL at University for Teacher Education in Tehran in 1990, then accomplished his MA studies at Tarbiat Modarres University in Tehran in 1994. He achieved his Ph.D. from Azad University, Science and Research Branch, Tehran, Iran in 2005. His dissertation was "The Wash back Effect of the UEE on EFL Education in Iran."

Dr. Nikoopour is a faculty member in TEFL Department at Islamic Azad University, Tehran, North Branch. He has published several papers in domestic and international academic journals so far. He is a member of the Editorial Board for some national and international journals related to TESOL. His research interests include language assessment, language learning strategies, teacher education, CALL, and learner variables.

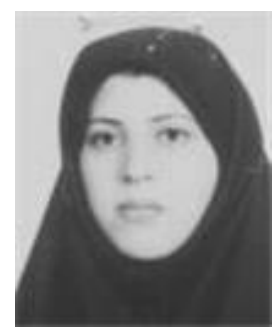

Nadimeh Esfandiari is an MA holder in TESOL, graduated from Islamic Azad University, Tehran, North Branch. She was born in 1976 in Tehran. She finished her BA studies in English Translation Studies in 2011, and accomplished her MA studies in TEFL in 2014. She has been teaching English at various levels for about ten years. She has shown great interest and creativity in her teaching career. Her research interests include language assessment, factors influencing language learning, teacher professional development. 